\title{
Endocrine Therapy Recommendation for Estrogen Receptor Positive (ER + ) Metastases Advanced Breast Cancer using Machine Learning Algorithms
}

Reena Lokare ( $\nabla$ reena.I@somaiya.edu )

K. J. Somaiya Institute of Engineering and Information Technology

Sunita Patil

K. J. Somaiya Institute of Engineering and Information Technology

\section{Research Article}

Keywords: Artificial Intelligence, Explainable Artificial Intelligence, Machine Learning, Deep Learning, Healthcare

Posted Date: March 10th, 2022

DOl: https://doi.org/10.21203/rs.3.rs-1378725/v2

License: (우 (i) This work is licensed under a Creative Commons Attribution 4.0 International License. Read Full License 


\section{Abstract}

Artificial Intelligence (Al) technology has shown tremendous contribution in various applications like Speech Recognition, Expert Systems, Computer Vision, Robotics, Gaming etc. Machine Learning (ML) and Deep Learning (DL) algorithms under Al address problems such as prediction, classification and regression. Al has touched many domains like Finance, Healthcare, Retail, Travel, Media etc. The results or the predictions generated by these algorithms are not easily accepted by the user with the apprehension as what Al promises, how can they guarantee it? Especially the Healthcare domain is facing a great challenge in accepting the results or the predictions with the concern, are Al results reliable, correct and ethical? Doctors or medical practitioners aren't ready to treat patients on the basis of results or suggestions generated by Al algorithms. Hence, a technology which can explain how the results returned by Al algorithms are trustworthy, transparent and interpretable was strongly needed. This need has given rise to the latest technology-Explainable Artificial Intelligence (XAI). With the use of XAI, all the predictions, classifications made by Al algorithms are explainable, auditable, comprehensive, validating and socially acceptable. This study will help medical practitioners and other researchers to use XAI for reliable, trustworthy and explainable results or suggestions provided by Al, ML, DL algorithms not only in healthcare but all other sectors adopting these technologies.

\section{Introduction}

World Health Organization has identified Cancer as the second leading cause of death globally. There are 18.1 million new cases and 9.6 million deaths due to cancer in the year 2021(2021). The number of Cancer patients alive with 5-year prevalence is nearly 43.8 billion. Once cancer is detected, the whole life of the patient along with their family, relatives \& neighborhood becomes a horrible threat.

Researchers \& Medical Practitioners are continuously working on finding the exact causes of cancer, but are unable to find all the causes (Adjiri et al.2016). When cancer is detected in its early stages, the chances of survival increase. But still, it is difficult to get complete rid from it. If cancer gets cured, there are chances that one type of cancer can lead to another type of cancer (Seyfried et al. 2013 and Eccles et al. 2007). With these complications, it is expected that doctors should prescribe most effective and personalized treatment to the patients so as to have minimal or no side effects. This thought has given rise to the concept of 'Precision Medicine' as stated by Krzyszczyk et al. (2018).

\subsection{Introduction to Multi-Omics Data}

The Multi-Omics data is multidisciplinary, molecular data. Linked Omics portal developed by Vasaikar et al. (2018) is one of the portals which not only gives access to multi-Omics data but facilitates data analysis and comparison of multi-Omics data with other profiles to detect disease if any. This data is playing a great role in prescribing proper cancer treatment. The Cancer Genome Atlas (TCGA) National Cancer Institute (2021) has developed first Human Genome. TCGA has molecular profile of tumor samples on Genomic, Epigenomic, Transcriptomic, Proteomic, etc. platforms.

Multi-Omics data is producing molecular profiles of tumor samples. It is helping researchers and doctors to understand an underlying disease and patient's health as stated by Subramanian et al. (2020).

As complex diseases like cancer, heart diseases demand suitable treatment, doctors need to understand the disease and patient's health well as mentioned by Whitcomb et al. (2019). By completely understanding patient's condition, patient-specific treatment is required in complex diseases (Ahmed et al. 2020).

\subsection{Cancer Genomics and Next Generation Sequencing}

Next Generation Sequencing (NGS) describes DNA Sequencing technology which has revolutionized genomic research (Nones et al. 2020). Using NGS, an entire human genome can be sequenced within a single day (Behjati et al. 2013). 
All NGS platforms perform sequencing of millions of small fragments of DNA in parallel. Bioinformatics analyses are used to piece together these fragments by mapping the individual reads to the human reference genome. Each of the three billion bases in the Human Genome is sequenced multiple times, providing high depth to deliver accurate data and an insight into unexpected DNA variation.

NGS can be used to sequence entire Genome or constrained to specific areas of interest, including all 22,000 coding genes (a whole exome) or small number of individual genes.

NGS is thus broadly applied as a valuable method for gaining insights into the genomic profile of a tumor. The adoption of NGS in clinical practice has grown tremendously in order to recommend personalized treatment approach.

\subsection{Cancer and Gene Mutation}

Genes are the basic genetic elements that together, in interaction with the environment, are decisive for the phenotypes. Genes are considered as the fragments of the DNA sequence that finally produce proteins (Jiang et al. 2013).

A gene mutation is a permanent alteration in the DNA sequence that makes up a gene, such that the sequence differs from what is found in the most people. Mutations range in size; they can affect anywhere from a single DNA building block (base pair) to a large segment of a chromosome that includes multiple genes (Loewe et al. 2008).

\subsection{Cancer Biomarkers}

Biomarkers are specific molecular characteristics observed in Cancer patients. They play a significant role in Cancer treatment, especially in Personalized Cancer treatment. Multi-omics data described in subsection 4.1 is nothing but molecular profiles of Cancer tumors. This data has varied biomarkers such as genes, mutated genes, cells, molecules, hormones, enzymes, etc.

(Goossens et al. 2015)

Cancer biomarkers are playing crucial role in Cancer Prognosis, Precision Medicine and Drug Discovery.

\subsection{Precision Medicine for Breast Cancer}

Complex diseases like Cancer, Heart diseases, Diabetes and nearly all major diseases need person- specific treatment due to large number of deaths observed. These diseases might be inherited or developed due to wrong life style, eating habits, drugs, etc. Majority of the times, these diseases are diagnosed after progression of the disease and hence less time remains for the treatment. An effective and quick treatment is expected in this crucial period. Due to different molecular profile, physical conditions, health condition, etc. of a patient, same treatment always doesn't suit to all patients. This situation has given rise to the concept of Precision Medicine as stated by Ginsburg et al. (2018).

Precision Medicine is nothing but the patient-specific treatment considering patient's characteristics such as genomic profile, disease's biomarkers, etc. The Precision Medicine can play a significant role in patient's survival by offering suitable treatment. It can be discovered and recommended using the Artificial Intelligence (Al) technology. Al algorithms can be used to discover suitable treatment from the available treatment records in the public repositories.

Recent study has found effective drugs in certain type of breast cancer which are tabularized below for the understanding in table 1.

Table 1. Survey of effective drugs in Breast Cancer according to gene mutation 


\begin{tabular}{|c|c|c|c|}
\hline Sr.No. & $\begin{array}{l}\text { Type of Breast } \\
\text { Cancer }\end{array}$ & Gene Mutation & Drug/s \\
\hline 1 & $\begin{array}{l}\text { Hormone receptor } \\
\text { positive } \\
\text { / Metastatic HER- } \\
2 \text { negative breast } \\
\text { cancer }\end{array}$ & PI3K or ESR1 & $\begin{array}{l}\text { CDK4/6 inhibitors like abemaciclib (Verzenio), } \\
\text { palbociclib (Ibrance) and ribociclib } \\
\text { (Kisqali),alpelisib (Piqray),Fulvestrant (Jeselsohn } \\
\text { et al. 2016), Lynparza (olaparib) }\end{array}$ \\
\hline 2 & $\begin{array}{l}\text { Pre- and } \\
\text { postmenopausal } \\
\text { women with } \\
\text { early-stage breast } \\
\text { cancer }\end{array}$ & CYP2D6 & $\begin{array}{l}\text { Tamoxifen (Pratt et al.2012), aromatase } \\
\text { inhibitors (Als), anastrozole, letrozole and } \\
\text { exemestane }\end{array}$ \\
\hline 3 & $\begin{array}{l}\text { Triple receptor- } \\
\text { negative breast } \\
\text { cancer }\end{array}$ & BRCA1, BRCA2 & $\begin{array}{l}\text { Platinum-based drugs cisplatin, carboplatin and } \\
\text { oxaliplatin (Turner et al. 2012) }\end{array}$ \\
\hline 4 & Luminal A & $\begin{array}{l}\text { PI3K/mTOR, FGFR 1, 2, KRAS, P53, } \\
\text { CYP2D } 6\end{array}$ & $\begin{array}{l}\text { TAM, fulvestrant, aromatase inhibitor (Jeibouei } \\
\text { et al. 2019) }\end{array}$ \\
\hline 5 & Luminal B & $\begin{array}{l}\text { PIK3CA, gain of CCND1 and CDK4, } \\
\text { moderate PTEN reduction, up-regulation } \\
\text { and autocrine activation of HER2 }\end{array}$ & $\begin{array}{l}\text { TAM, fulvestrant, aromatase inhibitor (Jeibouei et } \\
\text { al. 2019) }\end{array}$ \\
\hline 6 & HER-2 Positive & $\begin{array}{l}\text { PIK3CA, RAS, Src, NF-KB and PTEN, } \\
\text { truncated isoforms of HER2, stable HER2 } \\
\text { homodimers formation, over expression } \\
\text { of EGFR and HER-3 }\end{array}$ & $\begin{array}{l}\text { HER2 and Kinase inhibitor: lapatinib, } \\
\text { pertuzumab, trastuzumab and adotratuzomab } \\
\text { emtansine, immune cell activation } \\
\text { (Ertumaxomab) (Jeibouei et al. 2019) }\end{array}$ \\
\hline 7 & $\begin{array}{l}\text { Basal-like } \\
\text { Claudin-low }\end{array}$ & Mutation in TP53 & $\begin{array}{l}\text { PARPI inhibitor (olaparib and iniparib), cisplatin } \\
\text { (Jeibouei et al. 2019) }\end{array}$ \\
\hline
\end{tabular}

The literature surveyed above shows the recent advancement in the field of precision medicine using genomic data of cancer patients. The available literature is published in the last two years mostly; which shows the problem highlighted is very recent and has tremendous scope for the enhancement.

Deep learning model proposed by Chiu Y. et al. suffers from over fitting due to model complexity. Also, they predicted a large amount of training data in order to improve model accuracy. Currently, due to the high cost of molecular profiling, enough patients' data is not available (Chiu et al. 2019).

Lin Eugene et al. have implemented a multi-layer feed forward neural network with two hidden layers. This model lagged in validation of the results by other independent cohorts or dataset. The sensitivity and specificity of the model is not adequate enough to predict treatment response in clinical practice. The study is underpowered because of limited sample size used for the analysis (Lin et al. 2018).

Huang $\mathrm{C}$ et al. have developed Support vector machine (SVM) with recursive feature elimination (RFE) algorithm for the prediction of optimal drug therapies. They have made this algorithm available online so that research community gets opportunities for creative modifications and improvements of existing algorithms. They highlight a need of larger and more extensive datasets to be used in a model building process in order to improve the predictive accuracy of the model Huang et al. 2017.

Aayush Singhal et al. has developed a decision tree classifier for text mining for precision medicine. They have highlighted an issue of identifying correct disease related mutations which are useful in recommending precision medicine. They have developed an automated approach to find relevant disease-related mutations from biomedical literature. The obtained results indicate that this approach will greatly benefit curation of mutation-disease databases on a mass scale also (Singhal et al. 2016). 
Comparative studies of the literature reviewed in the form of parameters such as validation method used, important features are given in table 2.

Table 2. Comparison of Machine Learning approaches in Precision Medicine

\begin{tabular}{|c|c|c|c|c|c|c|c|}
\hline Publication & $\begin{array}{l}\text { Year of } \\
\text { Publication }\end{array}$ & $\begin{array}{l}\text { ML } \\
\text { Method }\end{array}$ & $\begin{array}{l}\text { No of } \\
\text { Patients }\end{array}$ & Type of data & Result & $\begin{array}{l}\text { Validation } \\
\text { method }\end{array}$ & $\begin{array}{l}\text { Important } \\
\text { Features }\end{array}$ \\
\hline $\begin{array}{l}\text { Predicting } \\
\text { drug response } \\
\text { of tumors } \\
\text { from } \\
\text { integrated } \\
\text { genomic } \\
\text { profiles by } \\
\text { deep neural } \\
\text { networks }\end{array}$ & $\begin{array}{l}\text { January, } \\
2019\end{array}$ & $\begin{array}{l}\text { Deep } \\
\text { Learning } \\
\text { Model }\end{array}$ & $\begin{array}{l}\text { 11,078: } \\
\text { tumors } \\
265: \\
\text { anti- } \\
\text { cancer } \\
\text { drugs }\end{array}$ & $\begin{array}{l}\text { gene } \\
\text { expression, } \\
\text { gene } \\
\text { mutation, } \\
\text { drug-response }\end{array}$ & $\begin{array}{l}\text { Mean Squared } \\
\text { Error: } 1.96 \\
\\
\text { (Superior than } \\
\text { Linear } \\
\text { Regression } \\
\text { and SVM) }\end{array}$ & $\begin{array}{l}\text { Bonferroni } \\
\text { test }\end{array}$ & $\begin{array}{l}\text {-over fitting } \\
\text { due to model } \\
\text { complexity } \\
\text {-Requirement } \\
\text { of large } \\
\text { training data }\end{array}$ \\
\hline $\begin{array}{l}\text { Deep Table } \\
\text { 1.5.1: Effective } \\
\text { drugs in Breast } \\
\text { Cancer } \\
\text { Learning } \\
\text { Approach for } \\
\text { Predicting } \\
\text { Antidepressant } \\
\text { Response in } \\
\text { Major } \\
\text { Depression } \\
\text { Using Clinical } \\
\text { and Genetic } \\
\text { Biomarkers }\end{array}$ & July, 2018 & $\begin{array}{l}\text { Multi-layer } \\
\text { feed } \\
\text { forward } \\
\text { neural } \\
\text { network } \\
\text { with } 2 \\
\text { hidden } \\
\text { layers }\end{array}$ & 455 & $\begin{array}{l}\text { Single } \\
\text { Nucleotide } \\
\text { Polymorphism } \\
\text { (SNP), age, } \\
\text { sex, baseline } \\
\text { Hamilton } \\
\text { Rating Scale } \\
\text { for Depression } \\
\text { score, } \\
\text { depressive } \\
\text { episodes, } \\
\text { marital status, } \\
\text { and suicide } \\
\text { attempt status } \\
\text { of MDD } \\
\text { patients }\end{array}$ & $\begin{array}{l}\text { AUC-area } \\
\text { under the } \\
\text { receiver } \\
\text { operating } \\
\text { characteristic } \\
\text { curve (AUC) = } \\
0.8228 \pm \\
0.0571 \\
\text {-sensitivity = } \\
0.7546 \pm \\
0.0619 \\
\text {-specificity = } \\
0.6922 \pm \\
0.0765\end{array}$ & $\begin{array}{l}10-f o l d \\
\text { cross- } \\
\text { validation }\end{array}$ & $\begin{array}{l}\text { phenotyped } \\
\text { antidepressant } \\
\text { response, } \\
\text { molecular } \\
\text { diagnostic, } \\
\text { prognosis tool }\end{array}$ \\
\hline $\begin{array}{l}\text { Open source } \\
\text { machine- } \\
\text { learning } \\
\text { algorithms for } \\
\text { the prediction } \\
\text { of optimal } \\
\text { cancer drug } \\
\text { therapies }\end{array}$ & $\begin{array}{l}\text { October, } \\
2017\end{array}$ & $\begin{array}{l}\text { Support } \\
\text { vector } \\
\text { machine } \\
\text { (SVM) with } \\
\text { recursive } \\
\text { feature } \\
\text { elimination } \\
\text { (RFE) }\end{array}$ & 60 & $\begin{array}{l}\text { gene } \\
\text { expression } \\
\text { profiles, drug- } \\
\text { sensitivity } \\
\text { profiles }\end{array}$ & Accuracy: $84 \%$ & $\begin{array}{l}\text { leave-one- } \\
\text { out crosss } \\
\text { validation }\end{array}$ & $\begin{array}{l}\text { open-source } \\
\text { availability }\end{array}$ \\
\hline $\begin{array}{l}\text { Text mining } \\
\text { for precision } \\
\text { medicine: } \\
\text { automating } \\
\text { disease- } \\
\text { mutation } \\
\text { relationship } \\
\text { extraction } \\
\text { from } \\
\text { biomedical } \\
\text { literature }\end{array}$ & April, 2016 & $\begin{array}{l}\text { c4.5 } \\
\text { Decision } \\
\text { Tree } \\
\text { Classifier }\end{array}$ & - & $\begin{array}{l}\text { Biomedical } \\
\text { literature } \\
\text { PubMed }\end{array}$ & $\begin{array}{l}\text { precision: } \\
0.904 \\
\\
\text { recall:0.856 } \\
\text { F- } \\
\text { measure:0.880 }\end{array}$ & $\begin{array}{l}10-\text { fold } \\
\text { cross- } \\
\text { validation }\end{array}$ & $\begin{array}{l}\text { disease- } \\
\text { related } \\
\text { mutations, } \\
\text { biomedical } \\
\text { literature }\end{array}$ \\
\hline
\end{tabular}

\section{li. Case Study With Breast Cancer Prediction Using Clinical And Genomic Dataset}

This section discusses breast cancer treatment dataset. The detailed study is performed to understand clinical as well as genomic features.

Dataset Exploration: 
Breast cancer dataset consisting of 1502 hormone receptor positive tumor samples with clinical data and treatment details is used in the present study. This dataset consists of patients in which hormonal therapy was failed. Some of the key features identified in the dataset are as mentioned below in Table 3:

Table 3

Hormonal Therapy Failure Dataset Table

\begin{tabular}{|c|c|c|c|c|}
\hline Details of Dataset & Independent Variables & & & $\begin{array}{l}\text { Dependent } \\
\text { Variable }\end{array}$ \\
\hline \multirow[t]{2}{*}{ Clinical Features } & \multicolumn{2}{|l|}{ Genomic Features } & \multirow[b]{3}{*}{$\begin{array}{l}\text { ERBB2, EGFR, KRAS, } \\
\text { MYC, FOXA1, TBX3, } \\
\text { SMARCB1, CCND1, } \\
\text { CDK4, MTOR, CDH1 }\end{array}$} & \multirow[b]{3}{*}{$\begin{array}{l}\text { Therapy } \\
\text { (Suitable/Not } \\
\text { Suitable) }\end{array}$} \\
\hline & Genes Mutated & Genes Amplified & & \\
\hline $\begin{array}{l}\text { Metastatic Breast Cancer - } \\
\mathrm{HR}^{+}(\text {Hormone receptor } \\
\text { Positive) dataset with } \\
\text { clinical and genomic } \\
\text { features. }\end{array}$ & $\begin{array}{l}\text { High-risk clinical features at } \\
\text { the time of diagnosis like } \\
\text { advanced stage, younger age, } \\
\text { premenopausal status, etc. }\end{array}$ & $\begin{array}{l}\text { NF1,HRAS,BRAF, } \\
\text { MAP2K1, ESR1, } \\
\text { ERBB2, ERBB3, } \\
\text { KRAS }\end{array}$ & & \\
\hline
\end{tabular}

The dataset is downloaded from CBioPortal. It was developed at Memorial Sloan Cancer Center (MSK). It is posted for public at url: cbioportal.org. The CBioPortal software is also available as open-source license on GitHub. This software is developed by multi-institutional team, consisting of MSK, the Dana Farber Cancer Institute, Princess Margaret Cancer Institute in Toronto, Children's Hospital of Philadelphia. The Hyve in the Netherlands and Bilkent University in Ankara, Turkey.

The CBioPortal not only provides datasets but also includes a research paper related to curation of every dataset. The research work which has received funding for the said research are mostly included in the portal. The research paper explains a complete procedure of dataset creation, observed features, research findings, etc. The datasets are made available for the research purpose.

The dataset used in the proposed research includes variety of data such as clinical, treatment and genomic data as discussed below.

\section{Clinical Data:}

The clinical data contains features related to clinical observations in breast cancer patients. There are features such as start time and end time of the treatment, reason behind stopping the treatment, details regarding tumor sample; such as time of sample collection, type of sample, site of sample, etc. The detailed type of cancer like HR, HER2 is also provided in the dataset. The time when primary cancer was detected in a patient, time when metastatic cancer was diagnosed in a patient, time between primary sample collection and disease diagnosis, age of patient, gender of patient, menopausal status of patient at the time of diagnosis of disease is also given in the dataset. The details of tumor such as overall tumor grade, nuclear grade, tumor stage is also mentioned. The status of patient at last follow-up, last contact time, death time, disease free survival in months, time of death, overall survival from the time of initial diagnosis is also mentioned in the dataset.

\section{Treatment Data:}

The treatment data consists of type of therapy given to patients, reason of stopping the therapy, etc.

The clinical data and treatment data is combined first to study treatment specific details based on the clinical features.

\section{Gene Alteration/Mutation Data and Amplified Data:}

The gene alteration data consists of genes altered; genes amplified in the patients. The altered genes produce different proteins. The dataset also includes details of protein produced by the altered genes. The amplified genes are also present in the dataset.

Cancer progresses through various pathological stages. These progressions are driven by the genetic alternations which causes change in gene pattern as shown in Fig. 1. The identification of altered genes provides new targets for early diagnosis and helps 
doctors in selecting suitable treatment strategy which is termed as precision medicine. These altered genes lead to metastatic cancer disease. It is observed that mutations in 32 genes were common in metastasis tumors compared with primary tumors.

Gene's amplification is an increase in number of copies of a gene sequence. Cancer cells sometimes produce multiple copies of genes in response to signals from other cells or their environment. The amplification of oncogenes- cancer causing genes, leads to progression of the disease. These amplified genes are useful target for prediction of suitable therapy or precision medicine.

Drug induced gene amplification results in drug resistance, due to increase in copies of genes.

The following graph in Fig. 2 shows the frequency of amplified genes.

The above graph shows amplification of genes. These are the genes which lead to hormonal therapy failure in breast cancer patients. The red bars in the graph indicate that the particular gene is amplified.

\section{Dataset exploration to find the reason of hormonal/endocrine therapy failure:}

\section{- Reason for stopping the treatment: Hormonal Therapy:}

The following graph shows reasons behind stopping the treatment in the patients. As seen in the plot of Fig. 3 , the main reason behind stopping the treatment is the end of the planned therapy. Nearly $30 \%$ patients have the ongoing hormonal therapy. Around $25 \%$ patients have disease progression due to hormonal therapy. Hence their treatment is stopped. Toxicity is observed in $10-15 \%$ of the patients and hence their treatment is stopped. Few reasons behind stopping the treatment are patient preference, change in treatment, break in treatment etc.

Figure 3. Bar plot showing reason of stopping the treatment in the Hormonal therapy failure dataset

The dataset includes clinical, genomic as well as treatment details. The treatment details are studied here in order to find out the reason behind treatment failure. This study focuses on hormonal or endocrine therapy.

- Therapies such as only hormonal therapy, hormone-CDK46i therapy and Anti-HER2 containing therapy are considered here.

\section{Treatments considered:}

Following treatments which includes hormonal therapy are considered here:

- Hormone-single

- Hormone-CDK46i

- Anti-HER2-containing

\section{Reason of stopping the treatment:}

The treatment data studied here records the reason of stopping the hormonal treatment. It includes following treatments:

- Switch treatment

- Disease progression

- Death

- Toxicity

It can be concluded that the treatment might be stopped because of unsuitability. Hence, it is clear that hormonal therapy can be avoided to these cancer subtypes.

Following Table 4 highlights reason of stopping the hormonal therapy according to cancer subtype. It shows that HR+/HER2cancer subtype has 5 patient samples who stopped the treatment due to change in treatment suggested may be due to 
unsuitability of the treatment. Also, $48 \mathrm{HR}+/ \mathrm{HER} 2$ - cancer subtype samples stopped treatment due to disease progression. Five cases stopped treatment due to death and six cases stopped treatment due to toxicity seen.

Disease progression is seen to be the major cause of stopping the treatment.

Table 4

Reason of stopping the hormonal therapy according to breast cancer subtypes

\begin{tabular}{|llllll|}
\hline Sr. No. & Breast Cancer Subtype & \multicolumn{4}{l}{ Reason of stopping the treatment (No. of samples) } \\
\cline { 3 - 6 } & & Switch Treatment & Disease Progression & Death & Toxicity \\
\hline 1 & HR+/HER2- & 5 & 48 & 5 & 6 \\
\hline 2 & HR-HER2+ & 7 & 50 & 7 & 8 \\
\hline 3 & HR + HER2+ & 8 & 51 & 8 & 9 \\
\hline 4 & HR-HER2- & 5 & 48 & 5 & 6 \\
\hline 5 & Triple Negative & 3 & 46 & 3 & 4 \\
\hline
\end{tabular}

The dataset is further explored to check number of metastatic cases, menopausal status and overall tumor grade in patients treated with hormonal therapy as shown in Table 5. It is seen that HR + HER2 + cancer subtype has maximum i.e., 9 cases of metastatic disease. Premenopausal status is seen in as high as 10 cases. Also, Maximum cases of tumor grade III are seen.

Table 5

Metastatic cases, menopausal status, tumor grade of samples treated with hormonal therapy

\begin{tabular}{|c|c|c|c|c|c|c|c|c|}
\hline \multirow[t]{2}{*}{$\begin{array}{l}\text { Sr. } \\
\text { No. }\end{array}$} & \multirow[t]{2}{*}{$\begin{array}{l}\text { Breast Cancer } \\
\text { Subtype }\end{array}$} & \multicolumn{2}{|c|}{$\begin{array}{l}\text { Metastatic } \\
\text { Disease }\end{array}$} & \multicolumn{2}{|c|}{$\begin{array}{l}\text { Menopausal } \\
\text { Status }\end{array}$} & \multicolumn{3}{|c|}{ Overall Tumor Grade } \\
\hline & & Yes & No & Pre & Post & $\begin{array}{l}\text { I- Low } \\
\text { Grade }\end{array}$ & $\begin{array}{l}\text { II -Intermediate } \\
\text { Grade }\end{array}$ & $\begin{array}{l}\text { Ill - } \\
\text { High Grade }\end{array}$ \\
\hline 1 & $\mathrm{HR}+/ \mathrm{HER} 2-$ & 2 & 0 & 1 & 1 & 0 & 0 & 2 \\
\hline 2 & HR-HER2+ & 8 & 8 & 10 & 8 & 5 & 5 & 5 \\
\hline 3 & HR + HER2+ & 9 & 9 & 10 & 9 & 7 & 7 & 12 \\
\hline 4 & HR-HER2- & 6 & 6 & 7 & 8 & 7 & 7 & 8 \\
\hline 5 & Triple Negative & 4 & 4 & 7 & 7 & 7 & 7 & 7 \\
\hline
\end{tabular}

\section{lii. Treatment Prediction Model Using Machine Learning Algorithms}

This section discusses the study of suitable therapy prediction for the treatment of breast cancer, with the help of machine learning algorithms like Decision tree classifier and support vector machine.

\section{Proposed Methodology}

The hormonal therapy failure dataset available in CBioPortal is used in current study. The combined dataset with clinical attributes, gene mutation information and treatment outcome details are used here. The clinical attributes records information related to breast cancer such as age, gender, type of breast cancer, HER2 status, HR status, tumor grade, menopausal state, etc. Gene mutation information gives details of gene mutated in patient both before and after treatment. Gene mutation includes details of mutated genes, amplified genes, deleted genes and fusion genes. This information plays a vital role in deciding suitable treatment on breast cancer. In case of hormonal therapy failure, some genes are identified to be mutated, amplified and deleted as well, as discussed in section 3 . These genes contribute in personalized treatment recommendation along with other attributes. The proposed methodology is as per Fig. 4. 


\section{Pre-processing}

The portal such as CBioPortal provides curated and preprocess data from microarray tests. Although preprocessing at genomelevel is not required, features having large number of missing values, and less important features are removed from the dataset.

\section{Algorithm}

\section{Treatment_Prediction (clinical data, genome data, treatment data)}

//Dataset preparation

1. $\mathrm{Dc}=$ Input Clinical data

2. $\mathrm{Dg}=$ Input Genomic data

3. $\mathrm{Dt}=$ Input Treatment data

4. $\mathrm{Dcg}=$ Map clinical and genomic data

5. Dcgt $=$ Map Dcg and treatment data

//Data preprocessing

1. Drop features with missing values.

2. Apply encoding function.

3. Extract breast cancer samples as per subtype such as HR + HER2-, HR-HER2+, HR + HER2+ ,HR-HER2- and Triple Negative.

4. Train machine learning model on Xtrain and Ytrain.

5. Test machine learning model on Xtest and Ytest.

6. Calculate performance of machine learning algorithms for all breast cancer subtypes.

// Result validation

1. Compare the predicted result with the reason of stopping the treatment.

2. Analyze the features used for prediction with the help of XAI.

\section{Results and Discussion}

Various machine learning algorithms are tested on treatment dataset. The performance of these algorithms is computed and compared. This section discusses various performance metrics.

\section{Sensitivity (Positive in treatment prediciton)}

Sensitivity is the ability of an algorithm to correctly predict suitable treatment for a patient.

Sensitivity $=T P /(T P+F N)$

$=$ Probability of being predicted treatment positive when treatment is suitable.

\section{Specificity (Negative in treatment prediciton)}

Specificity is the ability of an algorithm to correctly predict treatment not suitable for a patient.

Specificity $=\mathrm{TN} /(\mathrm{FP}+\mathrm{TN})$

$=$ Probability of being predicted treatment negative when treatment is not suitable.

\section{Accuracy}

Accuracy is one of the performance metric for evaluation classification model. Accuracy is nothing but the fraction of predictions correctly made by the classifer. Accuracy can be defined as follows 
$=(T P+T N) /(T P+T N+F P+F N)$

$=(1+296) /(1+296+3+0)=297 / 300=99 \%$

\section{Receiver Operating Characteristics (ROC)}

ROC curves feature true positive rate on $y$-axis and flase positive rate on the $y$-axis. The top-left corner of the plot is the ideal point- a false positive rate pf zero, and a true positive rate of one. This is not very realistic, but it means that a larger area under the curve (AUC) is usually better. The steepness of ROC curves is also important, since it is ideal to maximize the true positive rate while minimizing the false positve rate.

Table 6 shows parametrs used in treatment prediction in the current study. In case of positive test, true positive and false negative values of the classifier are used to predict suitable therapy. Similarly in case of negatiev test, false positive and true negative values of the classfiier are used to predict unisuitability of the therapy.

Table 6

Parameters used in treatment prediciton

\begin{tabular}{|lll|}
\hline & Therapy suitable & Therapy not suitable \\
\hline Test positive & TP & FP \\
\hline Test Negative & FN & TN \\
\hline & Sensitivity $=$ TP $/(T P+F N)$ & Specificity $=T N /(F P+T N)$ \\
\hline
\end{tabular}

Table 7 shows sensitivity and specificity calculated for predicting Anti HER2 therapy. It shows a detailed study of suitable and unsuitable therapies as per breast cancer subtype. The study has found that anti HER2 therapy is suitable for HER + breast cancers (Pernas et al. 2019). Application of decision tree classifier has found that Anti HER2 therapy doesn't suit HR+/HER2cancer and hence 294 out of 1501 cases are found to be predicted as unsuitable therapy. Chemotherapy is not suitable to 123 cases out of 1501 . Hormone CDK46i therapy is not suitable to 293 cases out of 1501 and hormone single therapy is not suitable to 198 cases out of 1502 . 
Table 7

Performance metrics for breast cancer subtype: HR+/HER2-

\begin{tabular}{|c|c|c|c|}
\hline \multirow[t]{2}{*}{ Breast Cancer Subtype } & \multirow[t]{2}{*}{ Decision Tree Classifier } & Therapy suitable & Therapy not suitable \\
\hline & & \multicolumn{2}{|l|}{ Anti HER2 Therapy } \\
\hline \multirow[t]{18}{*}{ HR+/HER2- } & Test positive & $1(\mathrm{TP})$ & $3(\mathrm{FP})$ \\
\hline & Test Negative & $0(\mathrm{FN})$ & 294(TN) \\
\hline & Sensitivity/Specificity & Sensitivity $=1 /(1+0)=100 \%$ & Specificity $=296 /(3+296)=98.99 \%$ \\
\hline & & \multicolumn{2}{|l|}{ Chemotherapy } \\
\hline & Test positive & 174 & 0 \\
\hline & Test Negative & 1 & 123 \\
\hline & Sensitivity/Specificity & Sensitivity = 172/(172 + 1) & Specificity = 127/(0 + 127) \\
\hline & & $=99.42 \%$ & $=100 \%$ \\
\hline & & \multicolumn{2}{|l|}{ Hormone-CDK46i Therapy } \\
\hline & Test positive & 6 & 1 \\
\hline & Test Negative & 0 & 293 \\
\hline & Sensitivity/Specificity & Sensitivity = 6/(6+0) & Specificity = 293/(1 + 293) \\
\hline & & $100 \%$ & $=99.65 \%$ \\
\hline & & \multicolumn{2}{|l|}{ Hormone Single Therapy } \\
\hline & Test positive & 97 & 1 \\
\hline & Test Negative & 4 & 198 \\
\hline & Sensitivity/Specificity & Sensitivity = 97/(97 + 4) & Specificity = 198/(1 + 198) \\
\hline & & $96.03 \%$ & $99.49 \%$ \\
\hline
\end{tabular}

The Roc curve plotted in Fig. 5 for HR + HER2- cancer shows that area under curve-AUC for class hormone CDH46i, hormone single therapy and chemotherapy is highest. But AUC for class Anti HER2 therapy is poor and shows unsuitability of the treatment.

Table 8 shows only 3 therapies: anti HER2 and chemotherapy are given to HR-/HER2 + breast cancer patients. Anti HER2 therapy is found to be suitable 12 cases out 53 and chemotherapy doesn't suit to 12 cases out of 53 . 
Table 8

Performance metrics for breast cancer subtype: HR-/HER2+

\begin{tabular}{|llll|}
\hline Breast Cancer Subtype & $\begin{array}{l}\text { Decision Tree Classifier } \\
\text { HR-/HER2+ }\end{array}$ & $\begin{array}{l}\text { Therapy suitable } \\
\text { Anti HER2 Therapy }\end{array}$ & Therapy not suitable \\
\hline Test positive & $($ TP $) 12$ & $($ FP $) 0$ \\
\hline Test Negative & $($ FN $) 1$ & $($ TN $) 0$ \\
\hline Sensitivity/Specificity & Sensitivity $=12 /(12+1)=92.30 \%$ & Specificity $=0 /(0+0)=0 \%$ \\
\hline Test positive & Chemotherapy & 1 \\
\hline Test Negative & 0 & 12 \\
\hline Sensitivity/Specificity & 0 & Sensitivity $=0 /(0+1)$ & Specificity $=12 /(1+12)$ \\
& $=0 \%$ & $=92.30 \%$ \\
\hline
\end{tabular}

Figure 6 shows Roc curve for HR-HER2 + breast cancer. The ROC graph shows only 2 therapies give to the patients, out of which AUC for chemotherapy is not seen, The AUC for Anti HER2 therapy if also seen to be almost high, showing not much suitability of the treatment to HR-/HER2 + cancer subtype.

Table 9. shows anti HER2 therapy was found suitable to 23 cases out of 179 and chemotherapy was found to be unsuitable to 29 cases out of 179 .

Table 9

Performance metrics for breast cancer subtype: HR+/HER2+

\begin{tabular}{|c|c|c|c|}
\hline \multirow[t]{2}{*}{ Breast Cancer Subtype } & \multirow[t]{2}{*}{ Decision Tree Classifier } & Therapy suitable & Therapy not suitable \\
\hline & & \multicolumn{2}{|l|}{ Anti HER2 Therapy } \\
\hline \multirow[t]{15}{*}{ HR+/HER2+ } & Test positive & (TP) 23 & $(\mathrm{FP}) 0$ \\
\hline & Test Negative & $(\mathrm{FN}) 0$ & $(\mathrm{TN}) 13$ \\
\hline & Sensitivity/Specificity & Sensitivity = $100 \%$ & Specificity = $100 \%$ \\
\hline & & \multicolumn{2}{|l|}{ Chemotherapy } \\
\hline & Test positive & 7 & 0 \\
\hline & Test Negative & 0 & 29 \\
\hline & Sensitivity/Specificity & Sensitivity = $100 \%$ & Specificity = 100\% \\
\hline & & \multicolumn{2}{|c|}{ Hormone-CDK46i Therapy } \\
\hline & Test positive & 5 & 0 \\
\hline & Test Negative & 0 & 31 \\
\hline & Sensitivity/Specificity & Sensitivity = $100 \%$ & Specificity = 100\% \\
\hline & & \multicolumn{2}{|c|}{ Hormone Single Therapy } \\
\hline & Test positive & 1 & 0 \\
\hline & Test Negative & 0 & 35 \\
\hline & Sensitivity/Specificity & Sensitivity = $100 \%$ & Specificity = $100 \%$ \\
\hline
\end{tabular}


Figure 7 shows three treatments were given to HR+/HER2 + breast cancer patients. Out of three treatments only one therapyHormone CDK46i has maximum AUC.

Table 10 shows study conducted for HR+/HER2 + breast cancer. It shows Anti HER2 therapy has been suited to 25 cases out of 125. Chemotherapy has been failed in 27 cases and hormone CDK46i therapy has been failed in 34 cases.

Table 10

Performance metrics for breast cancer subtype: HR+/HER2+

\begin{tabular}{|c|c|c|c|}
\hline \multirow[t]{2}{*}{ Breast Cancer Subtype } & \multirow[t]{2}{*}{ Decision Tree Classifier } & Therapy suitable & Therapy not suitable \\
\hline & & \multicolumn{2}{|l|}{ Anti HER2 Therapy } \\
\hline \multirow[t]{11}{*}{ Triple Negative } & Test positive & (TP)25 & $(\mathrm{FP}) 0$ \\
\hline & Test Negative & $(\mathrm{FN}) 0$ & $(\mathrm{TN}) 11$ \\
\hline & Sensitivity/Specificity & Sensitivity = $100 \%$ & Specificity = $100 \%$ \\
\hline & & \multicolumn{2}{|l|}{ Chemotherapy } \\
\hline & Test positive & 9 & 0 \\
\hline & Test Negative & 0 & 27 \\
\hline & Sensitivity/Specificity & Sensitivity = $100 \%$ & Specificity = $100 \%$ \\
\hline & & \multicolumn{2}{|c|}{ Hormone-CDK46i Therapy } \\
\hline & Test positive & 2 & 0 \\
\hline & Test Negative & 0 & 34 \\
\hline & Sensitivity/Specificity & Sensitivity = $100 \%$ & Specificity $=100 \%$ \\
\hline
\end{tabular}

Figure 8 shows three treatments were given to triple negative breast cancer patients. Out of which, Hormone CDH46i therapy is seen missing in ROC curve. Anti HER2 therapy and chemotherapy have good AUC for ROC curve.

\section{Result analysis and discussion}

The treatment prediction problem addressed here comes under multiclass classification problem. The dataset used considers treatment like chemotherapy, hormone therapy, etc.

This section highlights the machine learning algorithms used for treatment prediction.

Following Table 11 shows performance metrics for different machine learning algorithms. 
Table 11

Performance metrics of Machine Learning Algorithms

\begin{tabular}{|c|c|c|c|c|c|c|c|c|}
\hline \multirow[t]{2}{*}{$\begin{array}{l}\text { Sr. } \\
\text { No. }\end{array}$} & \multirow[t]{2}{*}{$\begin{array}{l}\text { Breast Cancer } \\
\text { Subtype }\end{array}$} & \multirow[t]{2}{*}{ Therapy } & $\begin{array}{l}\text { Accuracy } \\
(\%)\end{array}$ & $\begin{array}{l}\text { Sensitivity } \\
(\%)\end{array}$ & $\begin{array}{l}\text { Specificity } \\
(\%)\end{array}$ & $\begin{array}{l}\text { Precision } \\
\text { (\%) }\end{array}$ & $\begin{array}{l}\text { Recall } \\
(\%)\end{array}$ & $\begin{array}{l}\text { F1- } \\
\text { Score } \\
(\%)\end{array}$ \\
\hline & & & \multicolumn{6}{|c|}{ ML Algorithm: Decision Tree Classifier } \\
\hline \multirow[t]{4}{*}{1} & \multirow[t]{4}{*}{ HR+/HER2- } & Anti HER2 & 99.66 & 100 & 98.99 & 0 & 67 & 0 \\
\hline & & Chemotherapy & 99.33 & 99.42 & 100 & 99 & 99 & 99 \\
\hline & & $\begin{array}{l}\text { Hormone- } \\
\text { CDK46i }\end{array}$ & 100 & 100 & 99.65 & 100 & 100 & 100 \\
\hline & & Hormone single & 98.95 & 96.03 & 99.49 & 99 & 98 & 99 \\
\hline \multirow[t]{2}{*}{2} & \multirow[t]{2}{*}{ HR-HER2+ } & Anti HER2 & 100 & 92.30 & 0 & 100 & 100 & 100 \\
\hline & & Chemotherapy & 100 & 0 & 92.30 & 100 & 100 & 100 \\
\hline \multirow[t]{3}{*}{3} & \multirow[t]{3}{*}{ HR + HER2+ } & Anti HER2 & 100 & 100 & 100 & 92 & 100 & 96 \\
\hline & & Chemotherapy & 100 & 100 & 100 & 100 & 90 & 95 \\
\hline & & $\begin{array}{l}\text { Hormone- } \\
\text { CDK46i }\end{array}$ & 100 & 100 & 100 & 100 & 100 & 100 \\
\hline \multirow[t]{3}{*}{4} & \multirow[t]{3}{*}{ Triple Negative } & Anti HER2 & 100 & 100 & 100 & 100 & 100 & 100 \\
\hline & & Chemotherapy & 100 & 100 & 100 & 100 & 100 & 100 \\
\hline & & $\begin{array}{l}\text { Hormone- } \\
\text { CDK46i }\end{array}$ & 100 & 100 & 0 & 100 & 100 & 100 \\
\hline
\end{tabular}

Figure 9 showing a graph for comparing performance metrics decision tree classifier. It shows overall good performance of decision tree classifier.

Table 12 shows performance metrics of machine learning algorithms. It shows that decision tree classifier and support vector machine outperformed compared to other machine learning algorithms.

Figure 10 shows comparative study of performance metrics of machine learning algorithms applied.

Table 12

Performance metrics of Machine Learning Algorithms

\begin{tabular}{|llllll|}
\hline Sr. No. & Machine Learning Algorithm & $\begin{array}{l}\text { Accuracy } \\
(\%)\end{array}$ & $\begin{array}{l}\text { Precision } \\
(\%)\end{array}$ & $\begin{array}{l}\text { Recall } \\
(\%)\end{array}$ & $\begin{array}{l}\text { F1-Score } \\
\text { (\%) }\end{array}$ \\
\hline 1 & Decision Tree Classifier & 99 & 99 & 99 & 99 \\
\hline 2 & Random Forest & 89 & 86 & 89 & 87 \\
\hline 3 & K-Nearest Neighbor & 88 & 89 & 88 & 87 \\
\hline 4 & Naïve Bayes Classifier & 92 & 93 & 92 & 91 \\
\hline 5 & Support Vector Machine & 99 & 99 & 99 & 99 \\
\hline
\end{tabular}

\subsection{Validation of Results:}

In any healthcare application, validation of predictions by machine leaning model is important. Today lot of research is being carried out in the healthcare domain. ML technology is helping to solve numerous issues in healthcare such as disease 
prediction, drug recommendation, etc. Due to vast amount of research, validation of results is a biggest challenge. Doctors are unable to contribute in research work and hence result validation remains a challenge.

Due to availability of tools such as gene-drug association dataset (Griffith et al. 2013), vast amount of literature available in Pubmed, Nature journals, validation of results become achievable.

In the proposed research, validation of mutated genes is done. Table 13 shows mutated genes resists endocrine therapy through drug resistance.

In the similar way, genes which are deleted, amplified and causing resistance to endocrine therapy, can be validated.

Such mutated genes are biomarkers which help doctors in deciding suitable treatment to breast cancer patients and thus help in precision medicine.

Table 13

Impact of mutated genes on endocrine treatment and references

\begin{tabular}{|lll|}
\hline Gene Mutated & Impact on treatment & Source \\
\hline NF1 & Drug resistance & {$[34-35]$} \\
\hline HRAS & Drug resistance & {$[36-37]$} \\
\hline BRAF & Drug resistance & {$[38]$} \\
\hline MAP2K1 & Drug resistance & {$[39]$} \\
\hline ESR1 & Drug resistance & {$[40]$} \\
\hline ERBB2, ERBB3 & Drug resistance & {$[41]$} \\
\hline KRAS & Drug resistance & {$[42]$} \\
\hline
\end{tabular}

\section{Iv. Interpretation Of Ai/ml Model Implementation With Breast Cancer Case Study}

Machine learning algorithms used to make predictions in healthcare, must be made interpretable in order to be accepted by medical professionals.

Various machine learning algorithms are applied on breast cancer dataset to predict suitable treatment.

With the help of explainable Al technology, predictions made by machine learning algorithms can be interpreted as shown in figure.

The figure explains an individual prediction. It shows prediction probabilities of every output class in the left side. It also shows list of features contributed in prediction along with their value, in the right side of the Fig. 11.

The figure below shows chemotherapy treatment is predicted here. The features invasive carcinoma age, DFS (disease free months) month, end time, invasive carcinoma time contributes the positive prediction of chemotherapy. Whereas, treatment class, NGS sample collection time violates chemotherapy treatment prediction.

The Fig. 12 below shows a bar graph for the same prediction explained above. Here green bar indicates features supports the prediction. Whereas red color bar indicates violation of the features contributed in the prediction.

\section{Conclusion And Future Scope}

Machine learning algorithms can be used to predict suitable therapy for breast cancer as discussed in this chapter. The present study uses clinical data, genomic data and treatment data. A detailed study of clinical features, genomic features and treatment 
details is done here. In order to predict and recommend personalized treatment to the patients, gene mutation data is used here.

The existing study focuses only on hormonal therapy. In future, different breast cancer therapies such as chemotherapy, radiotherapy data can be used to predict suitable treatment.

Also, ensemble models can be used to combine result of treatment predictions and to gain more accurate results.

\section{Declarations}

Conflict of Interest: There is no conflict of interest in this research work.

Ethical Approval and Consent to participate: All patients whose sample were used in this analysis have signed the informed consent.

\section{Consent for Publication:}

Both the authors voluntarily give the consent for publishing our research work.

\section{Data Availability Statement:}

Data used in this study is available on cBioPortal online at https://www.cbioportal.org/study/summary?id=breast_msk_2018. The dataset presented in this study is available on request from the corresponding author.

\section{Funding:}

This research has no funding.

\section{Author's Contributions:}

Data collection and analysis: R.L., Attribute selection and EDA: S.P., Application of ML algorithms: R.L., Analysis of results: S.P., Conclusions and future scope: S.P.

\section{Acknowledgements:}

This research is supported by Dr. Suresh Ukarande, Principal, K. J. Somaiya Institute of Engineering and Information Technology, Mumbai.

We thank him for all the guidance and support provided in this research.

We also thank our family members for their kind support. 


\section{References}

1. World Health Organization, February 6, 2020, https://www.who.int/news-room/fact-sheets/detail/cancer.

2. Adjiri, Adouda. "Identifying and targeting the cause of cancer is needed to cure cancer." Oncology and therapy 4, no. 1 (2016): 17-33.

3. Seyfried, Thomas N., and Leanne C. Huysentruyt. "On the origin of cancer metastasis." Critical Reviews ${ }^{T M}$ in Oncogenesis 18, no. 1-2 (2013).

4. Eccles, Suzanne A., and Danny R. Welch. "Metastasis: recent discoveries and novel treatment strategies." The Lancet 369 , no. 9574 (2007): 1742-1757.

5. Krzyszczyk, Paulina, Alison Acevedo, Erika J. Davidoff, Lauren M. Timmins, Ileana Marrero-Berrios, Misaal Patel, Corina White et al. "The growing role of precision and personalized medicine for cancer treatment." Technology 6, no. 03n04 (2018): 79-100.

6. Vasaikar, Suhas V., Peter Straub, Jing Wang, and Bing Zhang. "LinkedOmics: analyzing multi-omics data within and across 32 cancer types." Nucleic acids research 46, no. D1 (2018): D956-D963.

7. National Cancer Institute, https://www.cancer.gov/about-nci/organization/ccg/research/structural-genomics/tcga. [Accessed: January 30,2021]

8. Subramanian, Indhupriya, Srikant Verma, Shiva Kumar, Abhay Jere, and Krishanpal Anamika. "Multi-omics data integration, interpretation, and its application." Bioinformatics and biology insights 14 (2020): 1177932219899051.

9. Whitcomb, David C. "Primer on precision medicine for complex chronic disorders." Clinical and translational gastroenterology 10, no. 7 (2019).

10. Ahmed, Zeeshan. "Practicing precision medicine with intelligently integrative clinical and multi-omics data analysis." Human Genomics 14, no. 1 (2020): 1-5.

11. Nones, Katia, and Ann-Marie Patch. "The Impact of Next Generation Sequencing in Cancer Research." (2020): 2928.

12. Behjati, Sam, and Patrick S. Tarpey. "What is next generation sequencing?." Archives of Disease in Childhood-Education and Practice 98, no. 6 (2013): 236-238.

13. Jiang, Rui, Xuegong Zhang, and Michael Q. Zhang, eds. Basics of bioinformatics: Lecture notes of the graduate summer school on bioinformatics of China. Springer Science \& Business Media, 2013.

14. Loewe, Laurence. "Genetic mutation." Nature education 1, no. 1 (2008): 113.

15. Goossens, Nicolas, Shigeki Nakagawa, Xiaochen Sun, and Yujin Hoshida. "Cancer biomarker discovery and validation." Translational cancer research 4, no. 3 (2015): 256.

16. Ginsburg, Geoffrey S., and Kathryn A. Phillips. "Precision medicine: from science to value." Health Affairs 37, no. 5 (2018): 694-701.

17. Jeselsohn, Rinath, William T. Barry, Ilenia Migliaccio, Chiara Biagioni, Jin Zhao, Jonas De Tribolet-Hardy, Cristina Guarducci et al. "TransCONFIRM: Identification of a Genetic Signature of Response to Fulvestrant in Advanced Hormone ReceptorPositive Breast Cancer." Clinical Cancer Research 22, no. 23 (2016): 5755-5764.

18. Pratt, Victoria M., Howard L. McLeod, Wendy S. Rubinstein, Stuart A. Scott, Laura C. Dean, Brandi L. Kattman, and Adriana J. Malheiro. "Medical genetics summaries [Internet]." (2012).

19. Hertz, Daniel L., N. Lynn Henry, and James M. Rae. "Germline genetic predictors of aromatase inhibitor concentrations, estrogen suppression and drug efficacy and toxicity in breast cancer patients." Pharmacogenomics 18, no. 5 (2017): 481499.

20. Turner, Nicholas C., and Andrew NJ Tutt. "Platinum chemotherapy for BRCA1-related breast cancer: do we need more evidence?." (2012): 1-3.

21. Jeibouei, Shabnam, Mohammad Esmael Akbari, Alireza Kalbasi, Amir Reza Aref, Mohammad Ajoudanian, Alireza Rezvani, and Hakimeh Zali. "Personalized medicine in breast cancer: pharmacogenomics approaches." Pharmacogenomics and personalized medicine 12 (2019): 59.

Page 17/23 
22. Chiu, Yu-Chiao, Hung-I. Harry Chen, Tinghe Zhang, Songyao Zhang, Aparna Gorthi, Li-Ju Wang, Yufei Huang, and Yidong Chen. "Predicting drug response of tumors from integrated genomic profiles by deep neural networks." BMC medical genomics 12, no. 1 (2019): 143-155.

23. Lin, Eugene, Po-Hsiu Kuo, Yu-Li Liu, Younger W-Y. Yu, Albert C. Yang, and Shih-Jen Tsai. "A deep learning approach for predicting antidepressant response in major depression using clinical and genetic biomarkers." Frontiers in psychiatry 9 (2018): 290.

24. Huang, Cai, Roman Mezencev, John F. McDonald, and Fredrik Vannberg. "Open source machine-learning algorithms for the prediction of optimal cancer drug therapies." PLoS One 12, no. 10 (2017): e0186906.

25. Singhal, Ayush, Michael Simmons, and Zhiyong Lu. "Text mining for precision medicine: automating disease-mutation relationship extraction from biomedical literature." Journal of the American Medical Informatics Association 23, no. 4 (2016): 766-772.

26. Centers for Disease Control and Prevention, February 6, 2020, https://www.cdc.gov/dhdsp/pubs/guides/bestpractices/clinical-decision-support.htm.

27. MD Anderson Cancer Center, February 6, 2020, https://mdanderson.libguides.com/c.php?g=451500\&p=3386231

28. BMJ Best Practice, February 6, 2020, https://www.bmj.com/company/bmj-resources/bmj-best-practice/.

29. EBMeDS, February 6, 2020, https://www.ebmeds.org/en/.

30. Medscape, February 6, 2020, https://www.medscape.com/.

31. National Cancer Institute, February 6, 2020, https://www.cancer.gov/publications/pdq.

32. UpToDate, February 6, 2020, https://www.uptodate.com/home.

33. Pernas, S., and S. M. Tolaney. "HER2-positive breast cancer: new therapeutic frontiers and overcoming resistance. Ther Adv Med Oncol 2019; 11: 1758835919833519."

34. Pearson, Alex, Paula Proszek, Javier Pascual, Charlotte Fribbens, Monee K. Shamsher, Belinda Kingston, Ben O'Leary et al. "Inactivating NF1 mutations are enriched in advanced breast cancer and contribute to endocrine therapy resistance." Clinical Cancer Research 26, no. 3 (2020): 608-622.

35. Sokol, E. S., Y. X. Feng, D. X. Jin, A. Basudan, A. V. Lee, J. M. Atkinson, J. Chen et al. "Loss of function of NF1 is a mechanism of acquired resistance to endocrine therapy in lobular breast cancer." Annals of Oncology 30, no. 1 (2019): 115-123.

36. Zhumakayeva, A. M., K. D. Rakhimov, I. M. Omarova, L. I. Arystan, and S. M. Adekenov. "Experimental, clinical and morphological analysis of H-Ras oncoproteins for locally advanced breast cancer." Open access Macedonian journal of medical sciences 7, no. 19 (2019): 3153.

37. Hanker, Ariella B., Dhivya R. Sudhan, and Carlos L. Arteaga. "Overcoming endocrine resistance in breast cancer." Cancer Cell 37, no. 4 (2020): 496-513.

38. Albanell, Joan, Julia Andrea Elvin, Siraj Mahamed Ali, Alexa Betzig Schrock, Jon Chung, Jo-Anne Vergilio, James Suh et al. "BRAF: An emerging target for triple-negative breast cancer." (2017): 1099-1099.

39. Omarini, Claudia, Maria Elisabetta Filieri, Stefania Bettelli, Samantha Manfredini, Shaniko Kaleci, Cecilia Caprera, Cecilia Nasso et al. "Mutational profile of metastatic breast cancer tissue in patients treated with exemestane plus everolimus." BioMed research international 2018 (2018).

40. Brett, Jamie O., Laura M. Spring, Aditya Bardia, and Seth A. Wander. "ESR1 mutation as an emerging clinical biomarker in metastatic hormone receptor-positive breast cancer." Breast Cancer Research 23, no. 1 (2021): 1-15.

41. Brett, Jamie O., Laura M. Spring, Aditya Bardia, and Seth A. Wander. "ESR1 mutation as an emerging clinical biomarker in metastatic hormone receptor-positive breast cancer." Breast Cancer Research 23, no. 1 (2021): 1-15.

42. Hwang, Ki-Tae, Byoung Hyuck Kim, Sohee Oh, So Yeon Park, Jiwoong Jung, Jongjin Kim, In Sil Choi, Sook Young Jeon, and Woo-Young Kim. "Prognostic role of KRAS mRNA expression in breast cancer." Journal of breast cancer 22, no. 4 (2019): 548-561.

43. Griffith, Malachi, Obi L. Griffith, Adam C. Coffman, James V. Weible, Josh F. McMichael, Nicholas C. Spies, James Koval et al. "DGIdb: mining the druggable genome." Nature methods 10, no. 12 (2013): 1209-1210. 


\section{Figures}

\section{Figure 1}

Graph showing frequency of gene alteration in Hormonal therapy failure dataset

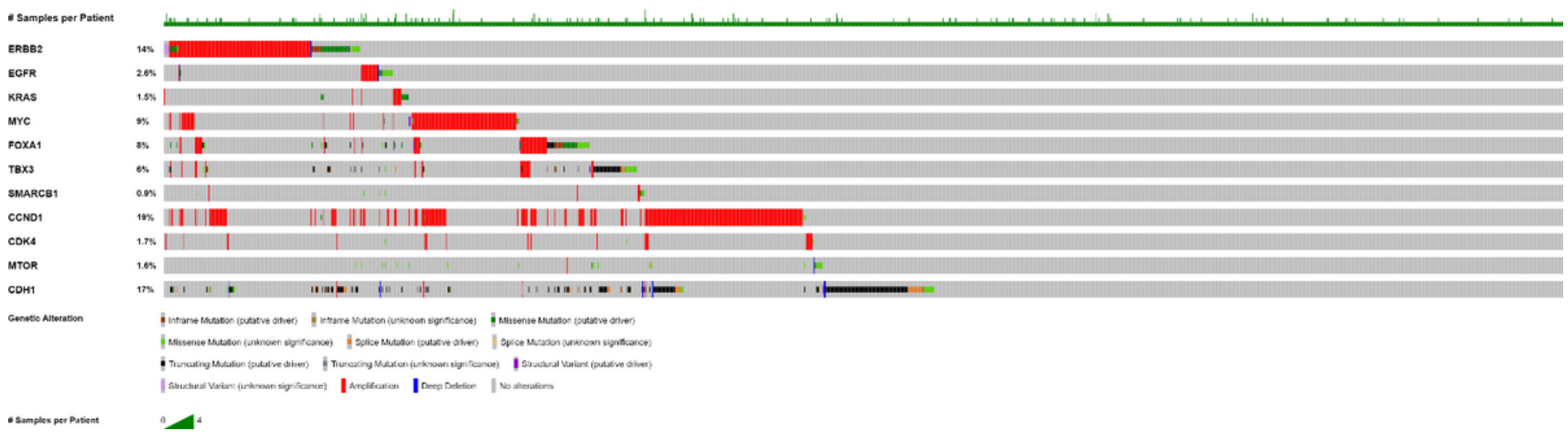

\section{Figure 2}

Genes Amplification Frequency Graph in Hormonal therapy failure dataset

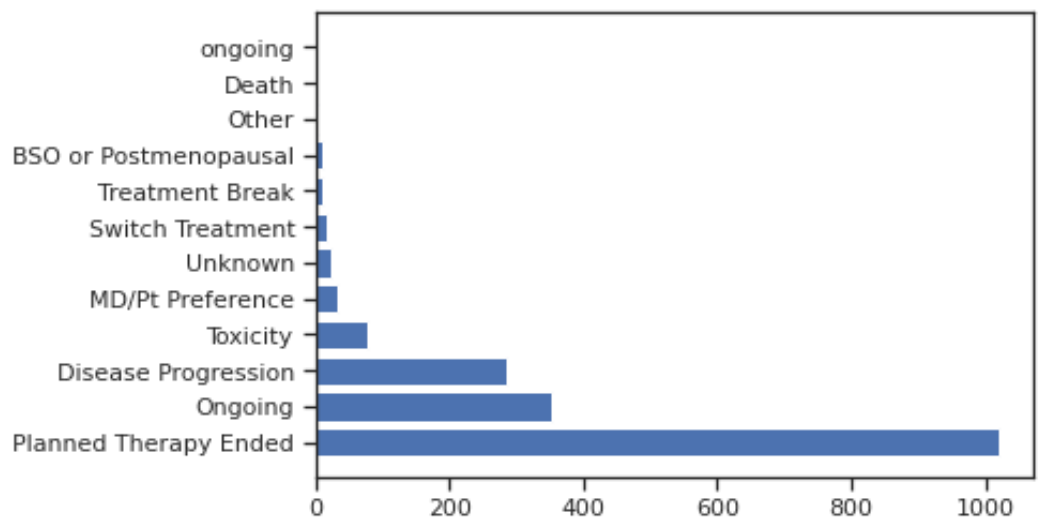

\section{Figure 3}

Bar plot showing reason of stopping the treatment in the Hormonal therapy failure dataset 


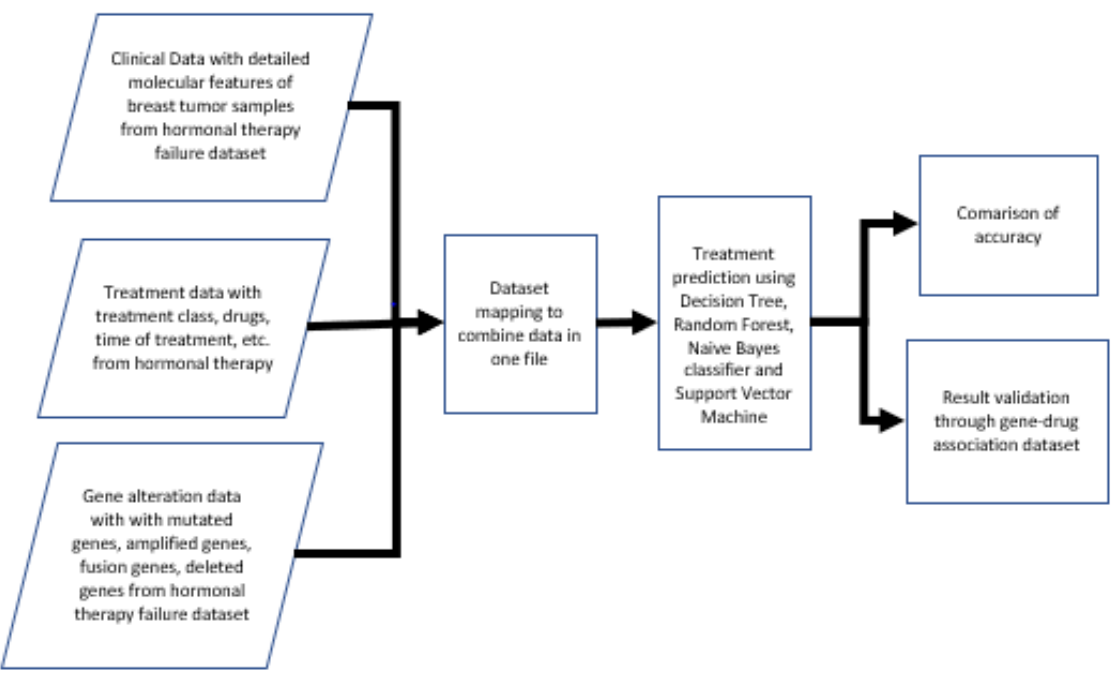

\section{Figure 4}

Methodology used for dataset preparation

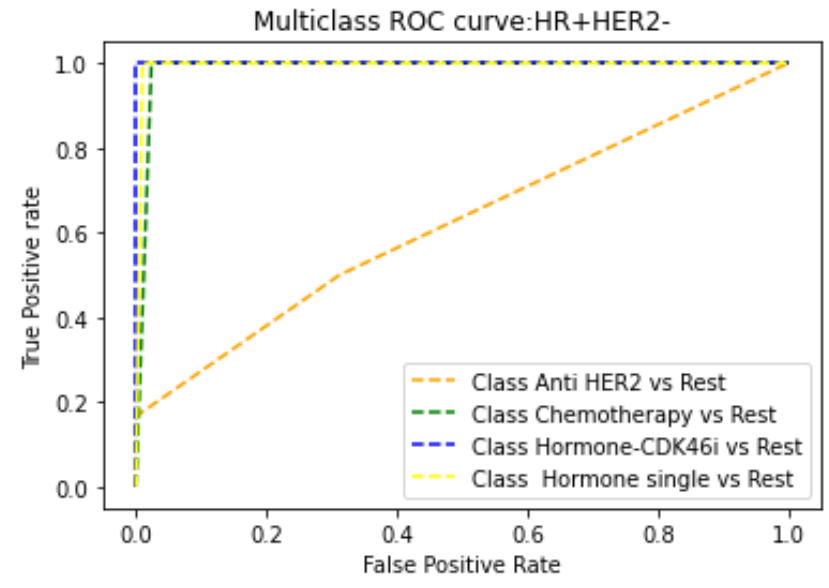

Figure 5

ROC curve for HR+HER2- breast cancer

\section{Figure 6}

ROC curve for HR-HER2+ 


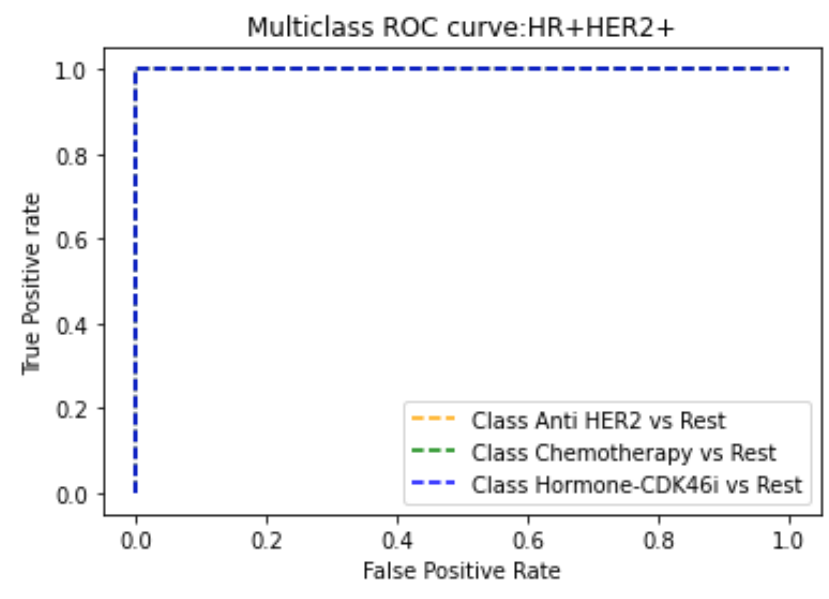

\section{Figure 7}

ROC curve for HR+HER2+

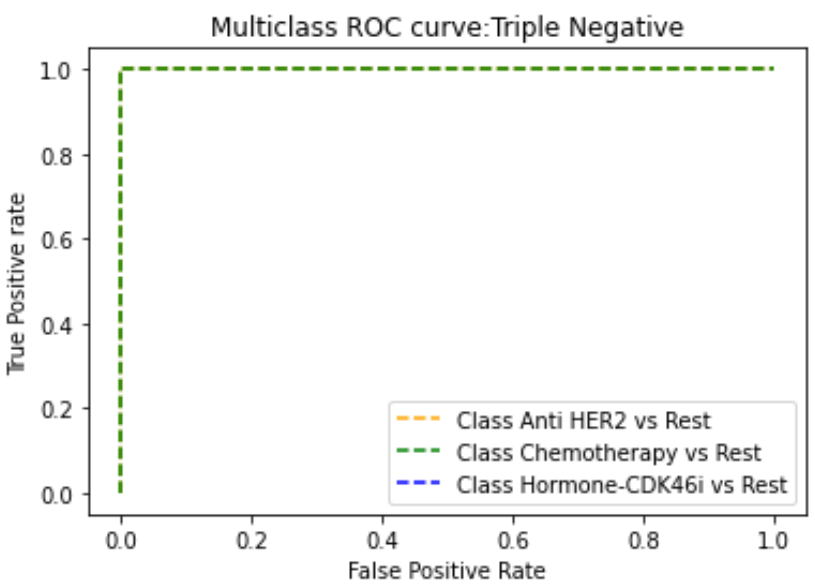

\section{Figure 8}

ROC curve for Triple Negative 


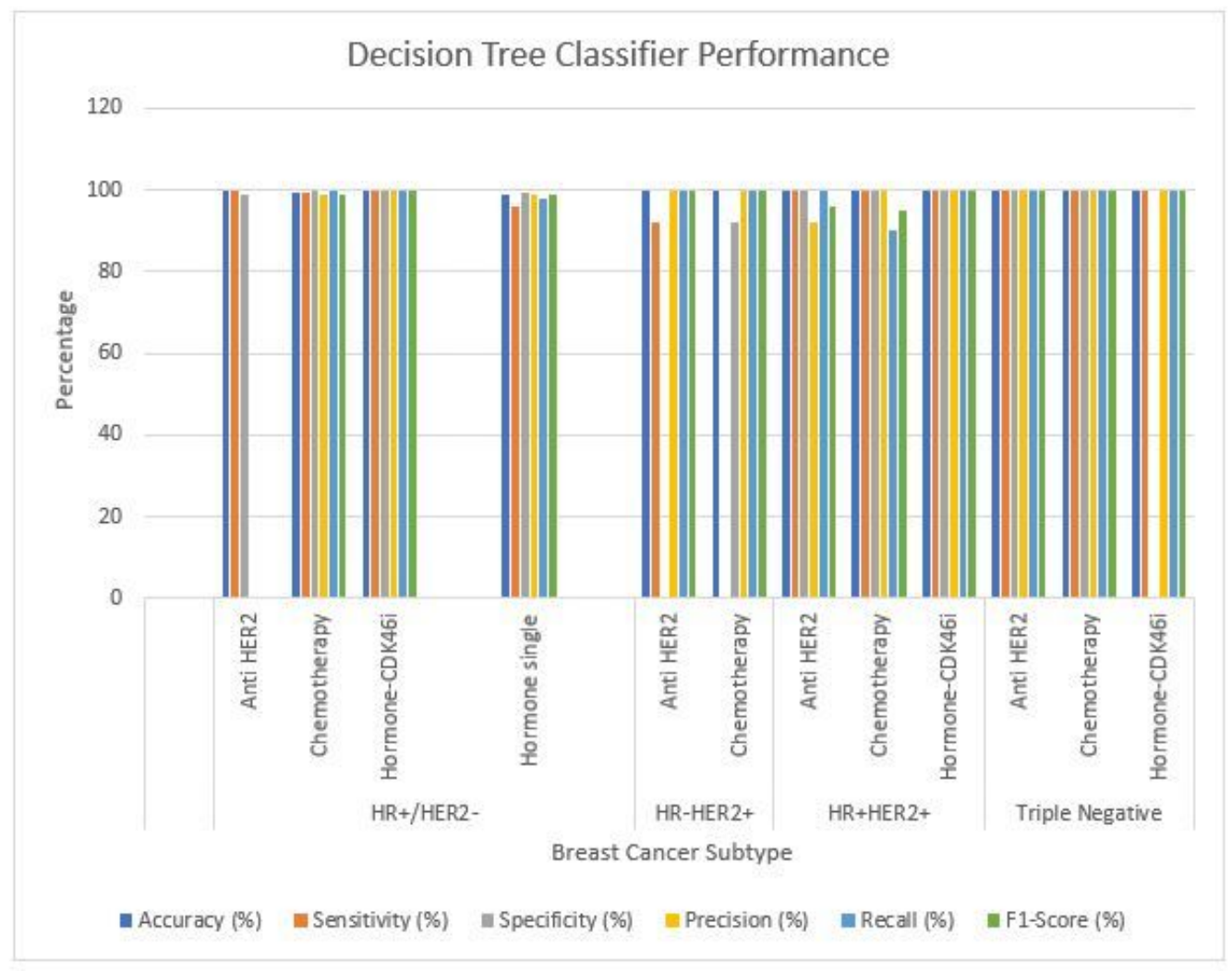

\section{Figure 9}

Graph showing comparison of performance metrics of decision tree classifier

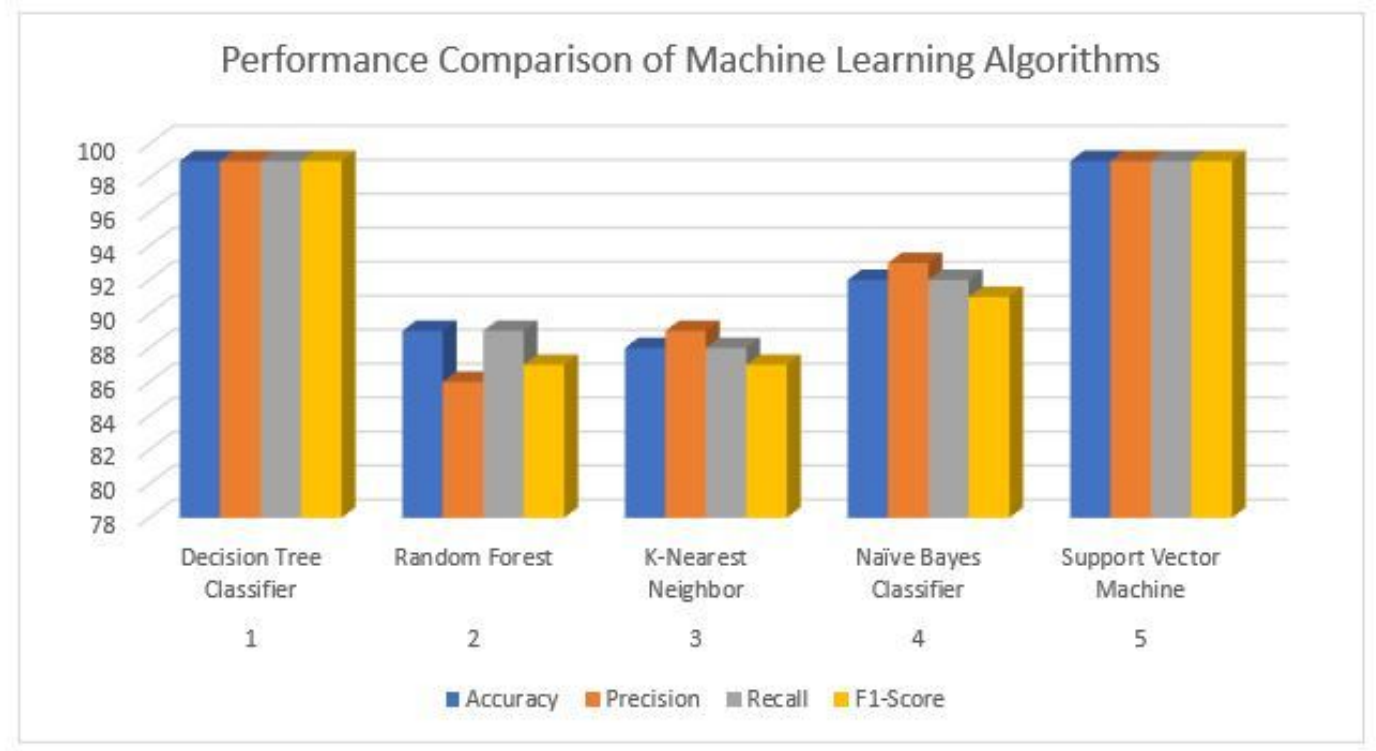

Figure 10

Graph showing accuracy, precision, recall and F1-score comparison of machine learning algorithms 

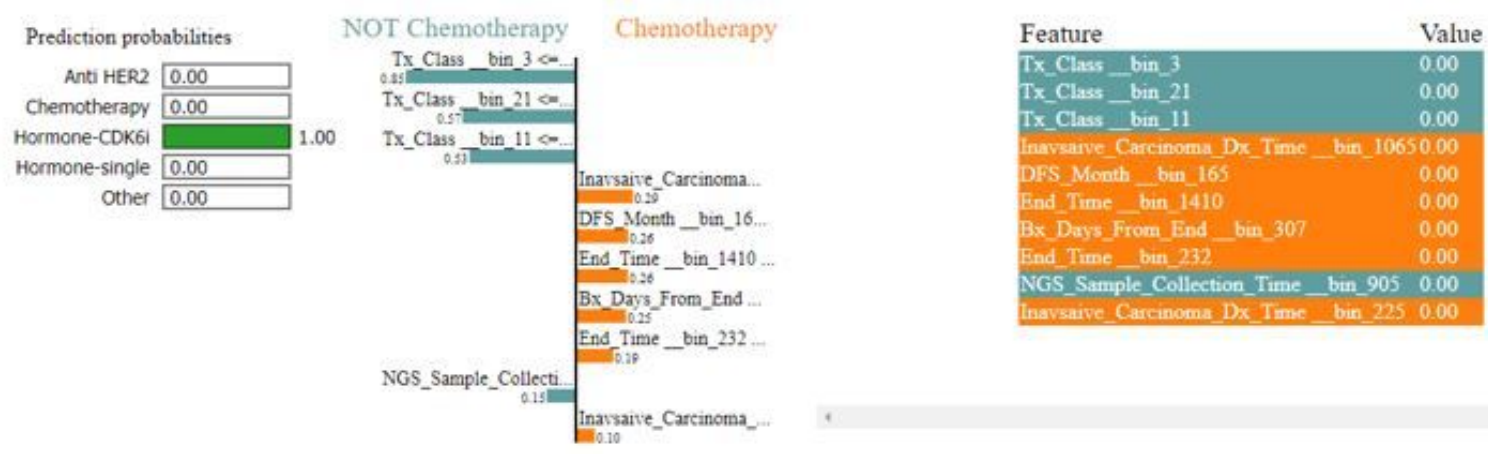

\section{Figure 11}

Interpretation of prediction made by decision tree classifier

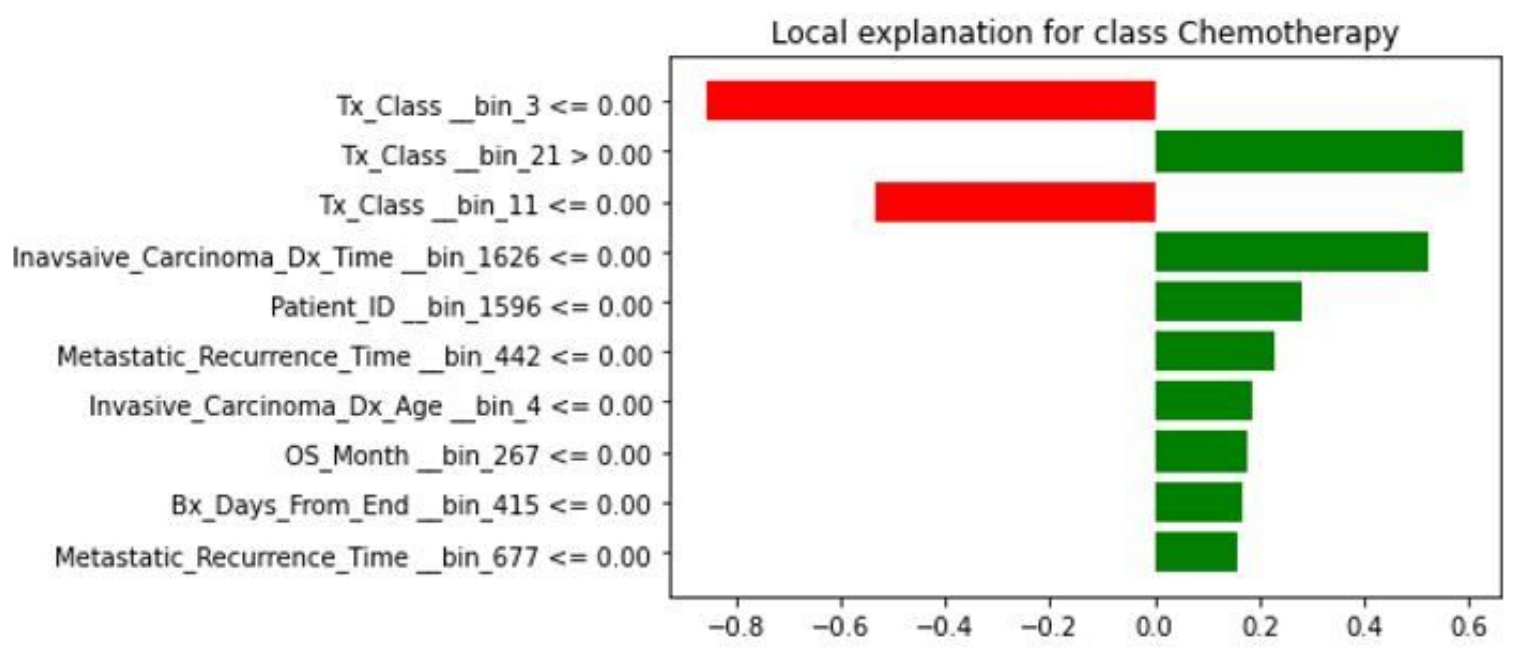

\section{Figure 12}

Bar graph showing feature importance in individual prediction of decision tree classifier 